Chapter 3

\title{
MONEY IN GENERAL EQUILIBRIUM THEORY
}

DARRELL DUFFIE*

Stanford University

\section{Contents}

1. Introduction 82

2. A simple model of monetary equilibrium $\quad 84$

$\begin{array}{ll}\text { 2.1. Preamble } & 84\end{array}$

2.2. The model 84

2.3. Efficiency 85

2.4. Assumptions 86

2.5. Existence of monetary equilibria $\quad 87$

2.6. Example $\quad 89$

2.7. Discussion 90

3. Inefficiency, indeterminacy, non-convexities, and incomplete markets 92

$\begin{array}{ll}\text { 3.1. General discussion } & 92\end{array}$

3.2. Incomplete markets with inside money: Indeterminacy and inoptimality 94

4. Concluding remark 97

References $\quad 98$

* The author is in debt to Frank Hahn, Kenneth Arrow, Jean-Michel Grandmont, David Levine, and John Roberts for useful conversations. The author is personally responsible for errors. This chapter was written in November 1986. 


\section{Introduction}

This chapter provides conditions for the existence of general monetary equilibrium in a simple setting, and discusses the role of money in general equilibrium theory. The phrase general monetary equilibrium evokes widely divergent images and interests. This chapter is sharply disciplined in focus, concentrating on the problems of pure outside fiat money in the setting of Arrow and Debreu (1954). The principal contribution of general equilibrium theory has been its axiomatic validation of our benchmark model of price taking, individual rationality, and market clearing. Equilibria exist, albeit under strong conditions. While monetary theorists continue to draw insights from this benchmark model, it has been difficult to find conditions implying any role for money in general equilibrium. As Hahn (1965) points out, the basic role of money as a medium of exchange is lost unless it also fills its role as a numeraire. If the value of money in relation to goods is zero, it cannot serve its purpose at all. This is worrisome in a finite horizon model. Since terminal money lays no apparent claim to goods or services, the terminal value of money would seem to be zero. This implies, by the same reasoning, that the value of money is zero in the penultimate period, and so on. Since we have yet to reach a terminal period in our real economy, devices used in the literature to induce a terminal value of money by forcing agents to return strictly positive amounts of money to the exchange authority after terminal trading seem innocuous in studying the properties of monetary equilibria, since these devices have smaller and smaller effects as the time horizon goes to infinity.

Nevertheless, and understandably, the unraveling value of money in finite horizon economies is such a stark and simple story that recent efforts to find monetary equilibria have concentrated on infinite horizon settings. Among these efforts, the results of Bewley (1980) and of Gale and Hellwig (1984) are seminal. In Bewley's infinite horizon model, uncertainty generates a precautionary demand for money. Since there are no other stores of value, agents hold money as insurance against shortfalls in endowment value. Driven by convexity of preferences, this effect is also present with purely deterministic fluctuations, and is the essence of the demand for money in the overlapping generations monetary models such as Black (1974) and Balasko and Shell $(1980,1981 \mathrm{a}, 1981 \mathrm{~b})$. As a store of value, money has difficulty in competing with interest-bearing assets, and the value of money may be driven out unless transactions costs give some advantage to money in relation to other assets. We see this transactions cost advantage modeled indirectly by adding cash-inadvance constraints [Clower (1967)], utility for holding money [Brock (1974)], credit verification costs [Woodford (1986)], or legal restrictions [Bryant and 
Wallace (1983)]. Gale and Hellwig (1984) address this problem head on, showing existence of monetary equilibria. In their model of an infinite number of identical infinitely lived agents, money competes as a store of value against investment in firms controlled individually by agents. Because payments of dividends by an agent's firm to the agent require a transactions cost, money can survive as a store of value. This follows the spirit of the early inventory models of demand for money of Baumol (1952), Miller and Orr (1956), and Tobin (1956). While the structure of the Gale-Hellwig model is special indeed, there are no known limits on its ultimate extensions.

To reopen the finite horizon discussion, however, one can find grounds for an extremely general and tractable class of models by re-examining the question of a terminal value for money. If monetary markets are operated by an authority set up for the common good, it is natural to suppose that the authority would be willing to collect money left at the market after terminal trading and to dispose of it. (This implies potential moral harzard on the part of agents employed by the authority to dispose of money, but most central banks manage to dispose of worn currency without much difficulty.) A mere accounting identity would then force the total value of purchases to exceed the total value of sales. In monetary markets, however, buying and selling are distinct activities and are commonly given distinct prices, and a value for money can indeed be accommodated in the bid-ask spread. In any case, this story leads precisely to the definition of an equilibrium given first by Foley (1970) (without money) and Hahn (1971) (without and then with money):

buying prices, selling prices, and optimal trades by agents given these prices, such that the total amount of each commodity (or money) bought is no greater than the total amount of each commodity (or money) sold.

Others, such as Starrett (1973), Kurz (1974a, 1974b, 1974c), Okuno (1973), and Hayashi (1974) have worked with this definition. The next section shows that this formulation is flexible enough to admit general monetary equilibrium in a static setting under standard regularity conditions, under the assumption: not trading at all is Pareto inefficient. After all, if money derives its value as a medium of exchange, equilibrium requires at least this latent demand for exchange. Existence with outside money based on this assumption resolves a dichotomy pointed out by Hayashi (1974), and extends naturally to the stochastic setting of Radner (1972), with security trading and incomplete markets. After showing existence of monetary equilibria in Section 2, we turn to an analysis of efficiency, indeterminacy, non-convexities, and incomplete markets in Section 3. 


\section{A simple model of monetary equilibrium}

\subsection{Preamble}

The following simple model promotes the view that there is a natural setting admitting existence of monetary equilibria. Yamazaki (1989) has extended the results to a richer setting with non-convexities. The two main aspects of this work that differ from earlier work are:

(i) (A place for money.) A non-zero bid-ask spread at any non-zero of volume of trade is maintained throughout the existence proof. Any trade then implies a value for money.

(ii) ( $A$ demand for money.) An assumption that Pareto-optimal allocations require trade generates a demand for monetary transactions services. Since "pure money" has value only as an efficient medium of exchange, one needs a demand for exchange in order to give positive value to money.

If, in the last period of a finite horizon economy, there is a non-zero price for money, then money has a non-zero price in preceding periods by virtue of its facility also as a store of value, as shown by Heller (1974) among others. Thus, in order to convince the reader that monetary equilibria exist in finite horizon economies, the onus is essentially to demonstrate monetary equilibria in a static model, with the pure outside fiat money features:

(i) no "utility" for, or "real backing" of, money,

(ii) strictly positive money endowments, and

(iii) no cash-in-advance constraints or requirements to "return money to authorities" after trade.

A lengthier discussion of the implications and motivation of our model follows the formal results.

\subsection{The model}

Our point of departure is the model of Foley (1970) and Hahn (1971). We take a static complete markets setting, leaving the extension to a stochastic incomplete markets economy for later work. As discussed, the essential technical difficulties rest with the static economy induced at the terminal date.

A set of $m$ agents is characterized, for each $i \in\{1, \ldots, m\}$, by a preference relation $\geq_{i} \subset \mathbb{R}_{+}^{l} \times \mathbb{R}_{+}^{l}$ over bundles of $l$ commodities, an endowment bundle $\omega_{i} \in \mathbb{R}_{+}^{l}$, an endowment $M_{i} \in[0, \infty)$ of money, and a transactions technology set $T_{i} \subset \mathbb{R}_{+}^{l} \times \mathbb{R}_{+}^{l} \times \mathbb{R}_{+}^{l}$, where $(b, s, z) \in T_{i}$ means that purchasing the bundle $b$ and selling the bundle $s$ can be accomplished at the cost of a bundle $z \in \mathbb{R}_{+}^{l}$. We write $x \geq_{i} y$ for $(x, y) \in \geq_{i}$ (meaning $x$ is preferred to $y$ ), and $x>_{i} y$ if 
$x \geq_{i} y$ and not $y \geq_{i} x$ (meaning $x$ is strictly preferred to $y$ ). We always take it that $\geq_{i}$ is complete (meaning either $x \geq_{i} y$ or $y>_{i} x$ for any $x$ and $y$ in $\mathbb{R}_{+}^{l}$ ) and transitive, meaning $x \geq_{i} y$ and $y \geq_{i} z$ imply that $x \geq_{i} z$. A choice $(b, s, z) \in T_{i}$ by agent $i$ leaves the consumption bundle $x_{i}=\omega_{i}+b-s-z$, and is budget feasible for $i$ at buying prices $p^{\mathrm{B}} \in \mathbb{R}^{l}$ and selling prices $p^{\mathrm{s}} \in \mathbb{R}^{l}$ provided $x_{i} \geq 0$ and

$$
p^{\mathrm{B}} \cdot b-p^{\mathrm{S}} \cdot s \leq M_{i} .
$$

The actual transaction procedure would be to receive $p^{\mathrm{s}} \cdot s$ in money, the unit of account, and spend at most the total amount of money $M_{i}+p^{\mathrm{s}} \cdot s$ in purchasing $b$. As did Foley (1970) and Hahn (1971), we view buying goods and selling goods as separate activities, at distinct exchange prices. At prices $\left(p^{\mathrm{B}}, p^{\mathrm{s}}\right)$, a budget feasible choice $(b, s, z)$ is optimal for $i$ provided $\omega_{i}+b-$ $s-z \geq_{i} \omega_{i}+b^{\prime}-s^{\prime}-z^{\prime}$ for any budget feasible choice $\left(b^{\prime}, s^{\prime}, z^{\prime}\right)$. A monetary equilibrium for $\left(\geq_{i}, \omega_{i}, M_{i}, T_{i}\right)$ is a collection

$$
\left(\left(b_{1}, s_{1}, z_{1}\right), \ldots,\left(b_{m}, s_{m}, z_{m}\right),\left(p^{\mathrm{B}}, p^{\mathrm{s}}\right)\right) \in\left(\mathbb{R}^{3 l}\right)^{m} \times \mathbb{R}^{2 l}
$$

such that, given prices $\left(p^{\mathrm{B}}, p^{\mathrm{S}}\right)$, the choice $\left(b_{i}, s_{i}, z_{i}\right) \in T_{i}$ is optimal for each $i \in\{1, \ldots, m\}$, and the allocation $\left\{\left(b_{i}, s_{i}, z_{i}\right)\right\}$ is feasible: $\sum_{i} b_{i} \leq \sum_{i} s_{i}$. This is the definition of Foley (1970) and Hahn (1971), except that transactions costs here are borne individually as in Heller (1974), rather than brokered by firms. Hahn (1971) has the added generality of a sequence of time periods.

\subsection{Efficiency}

As usual, feasible choices $\left\{\left(b_{i}, s_{i}, z_{i}\right)\right\}$ are efficient if there are no feasible choices $\left\{\left(b_{i}^{\prime}, s_{i}^{\prime}, z_{i}^{\prime}\right)\right\}$ such that $\omega_{i}+b_{i}^{\prime}-s_{i}^{\prime}-z_{i}^{\prime} \geq_{i} \omega_{i}+b_{i}-s_{i}-z_{i}$ for all $i$, with strict preference for some $i$. The following efficiency result will later be useful in proving existence, and will also reappear in the general discussion of efficiency in Section 3. The preference relation $\geq_{i}$ is semi-strictly convex if

$$
x>_{i} y \Rightarrow[\alpha x+(1-\alpha) y]>_{i} y
$$

for all $\alpha \in(0,1)$, and non-satiated at a choice $(b, s, z) \in T_{i}$ if there exists a choice $\left(b^{\prime}, s^{\prime}, z^{\prime}\right) \in T_{i}$ such that $\omega_{i}+b^{\prime}-s^{\prime}-z^{\prime}>_{i} \omega_{i}+b_{i}-s_{i}-z_{i}$.

Proposition 1. Suppose $\left(\left(\left(b_{1}, s_{1}, z_{1}\right), \ldots,\left(b_{m}, s_{m}, z_{m}\right)\right)\left(p^{\mathrm{B}}, p^{\mathrm{s}}\right)\right)$ is a monetary equilibrium with $p^{\mathrm{B}}=p^{\mathrm{s}}$. If , for all $i, T_{i}$ is convex and $\geq_{i}$ is semi-strictly convex and non-satiated at feasible choices, then the allocation $\left\{\left(b_{i}, s_{i}, z_{i}\right)\right\}$ is efficient. 
Proof. Suppose $\left\{\left(b_{i}^{\prime}, s_{i}^{\prime}, z_{i}^{\prime}\right)\right\}$ Pareto dominates $\left\{\left(b_{i}, s_{i}, z_{i}\right)\right\}$. For any $i$, let $(b, s, z) \in T_{i}$ be such that $\omega_{i}+b-s-z>_{i} \omega_{i}+b_{i}-s_{i}-z_{i}$. By semi-strict convexity,

$$
\omega_{i}+\alpha(b-s-z)+(1-\alpha)\left(b_{i}^{\prime}-s_{i}^{\prime}-z_{i}^{\prime}\right)>_{i} \omega_{i}+b_{i}-s_{i}-z_{i}
$$

for all $\alpha \in(0,1)$, implying that $p^{\mathrm{B}} \cdot\left[\alpha b+(1-\alpha) b_{i}^{\prime}\right]-p^{\mathrm{S}} \cdot\left[\alpha s+(1-\alpha) s_{i}^{\prime}\right]>$ $M_{i}$ for all $\alpha \in(0,1)$, implying that $p^{\mathrm{B}} \cdot b_{i}^{\prime}-p^{\mathrm{S}} \cdot s_{i}^{\prime} \geq M_{i}$ for all $i$ since $p^{\mathrm{B}} \cdot b_{i}-$ $p^{\mathrm{s}} \cdot s_{i} \leq M_{i}$. For some $i, p^{\mathrm{B}} \cdot b_{i}^{\prime}-p^{\mathrm{S}} \cdot s_{i}^{\prime}>M_{i}$. Thus $p^{\mathrm{B}} \cdot \Sigma_{i} b_{i}^{\prime}-p^{\mathrm{s}} \cdot \Sigma_{i} s_{i}^{\prime}>0$, which contradicts $p^{\mathrm{B}}=p^{\mathrm{S}}$ and $\Sigma_{i} b_{i} \leq \Sigma_{i} s_{i}$.

\subsection{Assumptions}

Turning to existence, we note that if money has value only as a medium of exchange and is in strictly positive supply, then monetary equilibrium must imply some demand for exchange, yielding our first assumption: the inefficiency of not trading.

(A.1) The allocation $0 \in \mathbb{R}^{3 l m}$ is not efficient.

Of course, if the total supply of money $M=\sum_{i=1}^{m} M_{i}$ is zero, then (A.1) can be dispensed with, so we offer an alternative:

(A.1') $M=0$.

Our next three assumptions are typical, although convexity of the transactions technology is objectionable. Remedies for non-convexities are discussed in Section 3.

(A.2) For all $i, T_{i}$ is closed, convex, and includes 0 .

(A.3) (Free disposal). For all $i$, if $(b, s, z) \in T_{i}$ and $\left(b^{\prime}, s^{\prime}\right) \in[0, b] \times[0, s]$, then $z^{\prime} \geq z \Rightarrow\left(b^{\prime}, s^{\prime}, z^{\prime}\right) \in T_{i}$.

(A.4) (Costly transactions). For all $i$, if $(b, s, z) \in T_{i}$ and $(b, s) \neq 0$, then $z \neq 0$.

We add an assumption that transactions costs are not so large as to make all strictly positive sales infeasible. By strictly positive sales $s$, we mean $s \in$ $\operatorname{int}\left(R_{+}^{l}\right)$, denoted $s \gg 0$. 
(A.5) For all $i$, there exists $(b, s, z) \in T_{i}$ such that $s \gg 0$.

We make strong assumptions on agents' preferences and endowments; these can be weakened along a traditional route by more complicated transactions assumptions, as in Kurz (1974a). The relation $\geq_{i}$ is strictly monotone if $[x \geq y \geq 0, x \neq y] \Rightarrow x>_{i} y$ and continuous if $\left\{x: x \geq_{i} y\right\}$ and $\left\{x: y \geq_{i} x\right\}$ are closed for all $y$ in $\mathbb{R}_{+}^{l}$.

(A6) For all $i, \geq_{i}$ is continuous, strictly monotone, semi-strictly convex, and non-satiated at feasible choices.

Assumption (A.6) is satisfied, for example, by preference relations represented by increasing strictly concave utility functions.

(A.7) For all $i, \omega_{i} \gg 0$.

\subsection{Existence of monetary equilibria}

Theorem 1. Under condition (A.1) or (A.1') and (A.2)-(A.7), there exist monetary equilibria for the economy $\left(\geq_{i}, \omega_{i}, M_{i}, T_{i}\right)$.

Proof. Let $\bar{A}$ be any diagonal $l \times l$ matrix with diagonal elements in $(0,1)$, let $I$ denote the $l \times l$ identity matrix, and let $\omega=\sum_{i=1}^{m} \omega_{i}$. For any $v \in[0, m \omega]$, let

$$
\Lambda(v)=\frac{\|v\|}{\|m \omega\|} \bar{\Lambda}+\frac{\|m \omega\|-\|v\|}{\|m \omega\|} I .
$$

Let $\Delta$ denote the unit simplex for $\mathbb{R}^{l}$. For purposes of this proof only, we normalize buying prices to this simplex, and express selling prices and the value $p^{M}$ of money relative to buying prices. We define the volume of trade, a useful technical concept, as the maximum $v \in \mathbb{R}^{l}$ (element-by-element) of the vectors $\bar{b}=\sum_{i} b_{i}$ and $\bar{s}=\sum_{i} s_{i}$ defining total purchases and sales. At buying prices $p \in \Delta$ and total volume of trade $v \in[0, m \omega]$, we set selling prices at $\Lambda(v) p$. We can then establish $\bar{p}^{M}=m[(I-\bar{\Lambda}) \mathbf{1}] \cdot \omega / M$, where $\mathbf{1}=(1,1, \ldots, 1)$, as an upper bound on the price of money relative to the buying prices of goods.

We have the constrained budget and demand correspondence as follows. For any $\left(v, p, p^{M}\right) \in[0, m \omega] \times \Delta \times\left[0, \bar{p}^{M}\right]$, let

$$
\begin{aligned}
\beta_{i}\left(v, p, p^{M}\right)= & \left\{(b, s, z) \in T_{i} \cap[0, \omega]^{3}: p \cdot b-[\Lambda(v) p] \cdot s \leq p^{M} M_{i}, \omega_{i}+b\right. \\
& -s-z \geq 0\},
\end{aligned}
$$




$$
\begin{aligned}
\varphi_{i}\left(v, p, p^{M}\right)= & \left\{(b, s, z) \in \beta_{i}\left(v, p, p^{M}\right): \omega_{i}+b-s\right. \\
& \left.-z \geq_{i} \omega_{i}+b^{\prime}-s^{\prime}-z^{\prime}, \forall\left(b^{\prime}, s^{\prime}, z^{\prime}\right) \in \beta_{i}\left(v, p, p^{M}\right)\right\}, \\
\varphi\left(v, p, p^{M}\right)= & \sum_{i=1}^{m} \varphi_{i}\left(v, p, p^{M}\right) .
\end{aligned}
$$

For any $(\bar{b}, \bar{s}) \in[0, m \omega]^{2}$, let $\tau(\bar{b}, \bar{s})=\{\max (\bar{b}, \bar{s})\}$, where $\max (\cdot, \cdot)$ denotes the element-by-element maximum function. This defines a volume-oftrade correspondence. For any $(\bar{b}, \bar{s}, v) \in[0, m \omega]^{3}$, let

$$
\mu(\bar{b}, \bar{s}, v)=\underset{p \in \Delta}{\arg \max } p \cdot(\bar{b}-v)+[\Lambda(v) p] \cdot(v-\bar{s}) .
$$

For any $(p, v) \in \Delta \times[0, m \omega]$, if $M=0$, let $\nu(p, v)=\left\{\bar{p}^{M}\right\}$; and if $M>0$, let

$$
\nu(p, v)=\{[p-\Lambda(v) p] \cdot v / M\} \subset\left[0, \bar{p}^{M}\right] .
$$

Finally, for any $\left[p, p^{M},(\bar{b}, \bar{s}, \bar{z}), v\right] \in \Delta \times\left[0, \bar{p}^{M}\right] \times[0, m \omega]^{3} \times[0, m \omega]$, let

$$
\psi\left[p, p^{M},(\bar{b}, \bar{s}, \bar{z}), v\right]=\mu(\bar{b}, \bar{s}, v) \times \nu(p, v) \times \varphi\left(v, p, p^{M}\right) \times \tau(\bar{b}, \bar{s}) .
$$

We may think of $\mu$ setting commodity prices to maximize the market value of excess demand; $\nu$ setting the relative price $p^{M}$ of money so as to clear the market for money; $\varphi$ as the total demand function for purchases, sales, and transactions inputs at relative prices $\left(p, \Lambda(v) p, p^{M}\right)$ for buying, selling, and money; and $\tau$ supplying a sufficient level of transactions services in both the purchases and sales markets.

By the continuity of $\Lambda$ and the usual arguments, $\mu$ has non-empty convex values and is upper semicontinuous. These conditions also apply obviously to the singleton-valued continuous correspondences $\nu$ and $\tau$. As for $\varphi$, one must show that $\varphi$ is upper semicontinuous; the other properties are quickly verified. For upper semicontinuity of $\varphi_{i}$, the only delicate point to check is lower semicontinuity of $\beta_{i}$. This follows from the usual argument. That is, given $\left(v_{n}, p_{n}, p_{n}^{M}\right) \rightarrow\left(v, p, p^{M}\right)$ and $(b, s, z) \in \beta_{i}\left(v, p, p^{M}\right)$, let $\left(b^{\prime}, s^{\prime}, z^{\prime}\right)$ be chosen so that $\omega_{i}+b^{\prime}-s^{\prime}-z^{\prime} \gg 0$ and so that $p \cdot b^{\prime}-[\Lambda(v) p] \cdot s^{\prime}<p^{M} M_{i}$. [This can be done by (A.2), (A.3), (A.5), and (A.7).] For $n$ sufficiently large, $\left(b^{\prime}, s^{\prime}, z^{\prime}\right)$ satisfies these same strict inequalities relative to $\left(v_{n}, p_{n}, p_{n}^{M}\right)$. For each $n$ sufficiently large, let $\alpha_{n} \in(0,1)$ be chosen so that

$$
\left(b_{n}, s_{n}, z_{n}\right) \equiv \alpha_{n}\left(b^{\prime}, s^{\prime}, z^{\prime}\right)+\left(1-\alpha_{n}\right)(b, s, z) \in \beta_{i}\left(v_{n}, p_{n}, p_{n}^{M}\right) .
$$


Since we can allow $\alpha_{n} \rightarrow 0$ with this property, $\beta_{i}$ is lower semicontinuous, and $\varphi_{i}$ is therefore upper semicontinuous. This implies that $\varphi$ is upper semicontinuous.

Since $\mu, \nu, \varphi$, and $\tau$ are non-empty valued, convex valued, and upper semicontinuous, $\psi$ inherits these properties, and has a fixed point $\left[p, p^{M},(\bar{b}, \bar{s}, \bar{z}), v\right]$ by Kakutani's Fixed Point Theorem. Since $\left(b_{i}, s_{i}, z_{i}\right) \in$ $\varphi_{i}\left(v, p, p^{M}\right) \Rightarrow p \cdot b_{i}-[\Lambda(v) p] \cdot s_{i} \leq p^{M} M_{i}$ for all $i$, and since $[p-\Lambda(v) p]$. $v=p^{M} M$ for $M>0$, we know that our fixed point has the property: $p \cdot(\bar{b}-$ $v)+[\Lambda(v) p] \cdot(v-\bar{s}) \leq 0$. Suppose, for some $k \in\{1, \ldots, l\}$, that $v_{k}>\bar{s}_{k}$. Let $q \in \Delta$ have $q_{k}=1$. Then, since $\bar{b}_{k}=v_{k}$ by definition of $\tau$, we have $q \cdot(\bar{b}-v)+$ $[\Lambda(v) q] \cdot(v-\bar{s})=\left(v_{k}-\bar{s}_{k}\right)>0$, a contradiction of the definition of $\mu$. Thus, $v \leq \bar{s}$, and therefore $\bar{b} \leq \bar{s}$, and there exist $\left(b_{i}, s_{i}, z_{i}\right) \in \varphi_{i}\left(v, p, p^{M}\right)$ for $i \in$ $\{1, \ldots, m\}$ such that $\sum_{i=1}^{m} b_{i} \leq \sum_{i=1}^{m} s_{i}$. If $p^{M} \neq 0$, it follows that

$$
\left(\left(b_{1}, s_{1}, z_{1}\right), \ldots,\left(b_{m}, s_{m}, z_{m}\right), p / p^{M}, \Lambda(v) p / p^{M}\right)
$$

is a monetary equilibrium, since the restriction of $\left(b_{i}, s_{i}, z_{i}\right)$ to $[0, \omega]^{3}$ is not a binding constraint, given that $s_{i} \leq \omega_{i}$ and the inoptimality of buying and selling the same commodity at prices $p^{\mathrm{S}} \leq p^{\mathrm{B}}$ under (A.4).

Suppose $p^{M}=0$. If $v=0$, then $\Lambda(v)=I$, and $((0,0,0), \ldots,(0,0,0), p, p$, is a monetary equilibrium for the economy $\left(\geq_{i}, \omega_{i}, 0, T_{i}\right), i \in\{1, \ldots, m\}$ (with zero money endowments). This, however, contradicts the inefficiency of no trade assumption (A.1) and Proposition 1. If $v \neq 0$, then $\bar{s}_{k}>0$ for some $k \in\{1, \ldots, l\}$. But strict monotonicity (A.6) then implies that $p_{k}>0$, implying that $p_{k} v_{k}>0$, yielding the contradiction $p^{M}>0$. Thus, $p^{M}>0$, and the proof is complete.

For the existence of equilibrium without free disposal of commodities, somewhat stronger conditions on the transactions technology sets will suffice, as shown by Kurz (1974a). One requires that the equilibrium buying price of any commodity is not zero, which follows, for example, if one can always be made strictly better off by buying some of a commodity for free and incurring the transactions costs. Our discussion of the efficiency and determinacy of monetary equilibria in Section 3 will hinge partly on the above method of proof, which implies existence of a class of equilibria with interesting properties.

\subsection{Example}

We display a simple example of monetary equilibria for two agents and two commodities. Let $\geq_{1}$ and $\geq_{2}$ be represented by the same utility function 
$u: \mathbb{R}_{+}^{2} \rightarrow \overline{\mathbb{R}}$ defined by $u(x)=\log \left(x_{1}\right)+\log \left(x_{2}\right)$ for $x \gg 0$ and $u(x)=-\infty$ otherwise. Let $T_{1}=T_{2} \subset \mathbb{R}_{+}^{6}$ be defined by $(b, s, z) \in T_{i} \Leftrightarrow z_{k} \geq 0.1\left(b_{k}+s_{k}\right)$ for $k \in\{1,2\}$, or a 10 percent transactions loss. Let $\omega_{1}=(8.1,12.1)$ and $\omega_{2}=$ $\left(\frac{119.9}{9}, \frac{80.1}{11}\right)$. Let $M_{1}=0$ and $M_{2}=2$. We claim that the prices $p^{\mathrm{B}}=(10,11)$ and $p^{\mathrm{s}}=(9,10)$; the trades $b_{1}=(1,0), s_{1}=(0,1)$ and $b_{2}=(0,1), s_{2}=(1,0)$; and the transactions costs $z_{1}=z_{2}=(0.1,0.1)$ determine a monetary equilibrium. The resulting allocation is $x_{1}=(9,11)$ and $x_{2}=(11 / 0.9,9 / 1.1)$. Budget feasibility follows easily. The first-order conditions for agent 1 at $\left(b_{1}, s_{1}, z_{1}\right)$ are satisfied, since

$$
\frac{\left(p_{1}^{\mathrm{B}}, p_{2}^{\mathrm{S}}\right)}{100}=\left[(1-\tau) \cdot \frac{\partial u\left(x_{1}\right)}{\partial x_{11}},(1+\tau) \cdot \frac{\partial u\left(x_{1}\right)}{\partial x_{12}}\right]=\left(\frac{1-\tau}{x_{11}}, \frac{1+\tau}{x_{12}}\right)
$$

and

$$
\frac{p_{1}^{\mathrm{S}}}{100}<\frac{1+\tau}{x_{11}}, \quad \frac{p_{2}^{\mathrm{B}}}{100}>\frac{1-\tau}{x_{12}},
$$

where $\tau=0.10$ is the minimal transactions loss. Similarly, the first-order conditions for agent 2 are satisfied, and we have a monetary equilibrium. We note that this economy satisfies all of the conditions (A.1)-(A.7) of our existence theorem. In particular, not trading is inefficient. This ends the example.

\subsection{Discussion}

Although many scenarios present themselves in support of our formulation, we might imagine the following one.

A monetary authority operates markets of exchange of $l$ commodities for money at each time $t$ in $\{0,1, \ldots, T\}$ at commodity spot purchase prices $p_{t}^{\mathrm{B}} \in \mathbb{R}^{\prime}$ and spot sales prices $p_{t}^{\mathrm{s}} \in \mathbb{R}^{\prime}$. (These prices and other quantities may be random.) We may have $p_{t}^{\mathrm{B}} \neq p_{t}^{\mathrm{S}}$ in equilibrium, since transactions costs may be severe enough to prevent arbitrage over the bid-ask spread: $p_{t}^{\mathrm{B}}-p_{t}^{\mathrm{S}}$. If the total volume of trade in period $t$ is $v_{t} \in \mathbb{R}^{l}$, then the amount of money added to the economy in period $t$ is $\Delta M_{t}=\left(p_{t}^{\mathrm{S}}-p_{t}^{\mathrm{B}}\right) \cdot v_{t}$, an accounting identity. The monetary authority has no preferences, does not consume, and is able to costlessly dispose of commodities and money left at the market after trade. We are thinking of money as currency, rather than its creditory forms, and thus require non-negative balances of money by agents. One could also add credit or securities such as futures, bonds, or deposits to the model. In fact, there may also be a barter sector at different exchange prices $p_{t}$. For simplicity, we 
have implicitly assumed that the barter transactions technology is dominated by the monetary exchange technology, as did Hahn (1971) and Heller (1974). More generally, an equilibrium would involve a mixture of barter and monetary transactions [Kurz (1974c)], but the spirit of our analysis covers this case, and a generalization to a mixed-exchange model is easy. Since mixed equilibrium allocations at $p_{t}^{\mathrm{B}}=p_{t}^{\mathrm{S}}$ are Pareto optimal by the same "adding up" argument of Arrow (1951) and Debreu (1954) used in the proof of Lemma 1, one must only make regularity condition (A.1) apply to trades in the monetary sector. One would also expect to find a mixture of brokered and individualistic transactions technologies. Many have assumed a purely brokered technology run by firms. We follow Heller's (1974) purely individualistic transactions technology for simplicity, making for a pure exchange model. Our results will hold up under the purely brokered convention, or under a mixture of individualistic and brokered transactions.

Now, in a particular state of the world, after payment of dividends of all securities at the last period $T$, we are left with an economy $\left(\geq_{i}, \omega_{i}, M_{i}, T_{i}\right)$, as in our formulation. If a monetary equilibrium for the economy exists, then a natural demand for money as a store of value exists at time $T-1$, at least in those states of the world for which $\left(\geq_{i}, \omega_{i}, M_{i}, T_{i}\right.$ ) emerges at time $T$ with positive conditional probability. There is thus a natural source of value for money at time $T-1$. Of course, given positive time preference or time fluctuations in consumption, bonds may also act as a store of value with a rate of return that dominates the return on money. Without transactions costs, this would drive out any value for money. Given transactions costs, selling money and buying bonds at $T-1$, and then selling at time $T$ bonds for consumption (which may be very cumbersome) or bonds for money, can be more costly than holding money between $T-1$ and $T$ at a lower (gross) return. One can easily imagine that agents generally choose to hold money between successive periods of sufficiently short duration, rather than incurring the costs of converting deposits or securities for every transaction.

This story is well understood and can be found, for example, in Heller (1974). The object of our formal model is to provide a foundation for the missing link: a terminal value for money. The fact that agents do not end up holding money after exchange at time $T$ is hardly surprising, and not contradictory of any natural aspects of our economy. If a terminal period were really "announced", one should be confident that agents will indeed sell all money, so long as converting money itself is not a costly transaction. (Incidentally, adding a transactions cost to exchange of money will not overturn our existence result.) Furthermore, the exchange authority can induce agents to acquire money in an initial period, rather than directly endowing agents with money, by offering a negative bid-ask spread at time zero. The same device used in our proof applies in this case. In particular, one need not use an infinite 
horizon model to study monetary equilibria, although an infinite horizon model may allow convenient time-independent representations of equilibria.

In our simple model, money is neutral, in the sense that an equilibrium allocation is still an equilibrium allocation for any strictly positive scaling of commodity prices and money endowments. Money is not inessential, a distinction of Hahn (1973a), in the sense that the presence of money, in particular its distribution among agents, has real allocational effects. Transactions costs do not pay an important role in the proof of Theorem 1 . One may conjecture that existence also obtains without transactions costs. The underlying natural model that includes a barter sector, however, would call for distinctions in the relative transactional efficiency of the monetary sector. This is in line with the view of Hicks (1935): that we will not make convincing progress in understanding the role of money in markets until we come to grips with transactional frictions.

\section{Inefficiency, indeterminacy, non-convexities, and incomplete markets}

\subsection{General discussion}

Many readers know that the topics inefficiency, indeterminacy, and nonconvexity are closely related, particularly in the context of monetary equilibria. We briefly review these issues. For simplicity of exposition, we often use differentiable notions, some of which extend by the use of convex analysis.

There are at least three sources of inefficiency in both monetary and non-monetary economies.

(i) In a model with a sequence of markets under uncertainty, an absence of complete forward markets can prevent agents from equating their marginal rates of substitution among bundles of goods that are not available through markets. Thus, certain technologically feasible transfers of goods by other than market feasible transactions can Pareto improve an equilibrium allocation.

(ii) With distinct markets for buying and selling, such as one would find in a monetary economy, it can happen that buying prices differ from selling prices, and agents' marginal rates of substitution can therefore differ even among marketed bundles of goods, another potential source of inefficiency.

(iii) Typical convexity assumptions are often unrealistic, especially for transactions technologies, which are thought to demonstrate increasing returns to scale. With non-convexities (in either preferences or production technologies), equating marginal rates of substitution among agents to marginal costs of firms is necessary but not sufficient for Pareto optimality. Value-maximizing firms with increasing returns to scale, moreover, will not necessarily produce so as to equate prices with marginal costs.

We have not even mentioned asymmetric information, also a potential 
source of inefficiency, as it has yet to be dealt with satisfactorily even in non-monetary general equilibrium theory. As commented by Hahn (1980), various sources of inefficiency are so endemic that a discussion of Pareto optimality in the context of monetary theory may be placing undue stress on the role of money in inefficiencies. To the contrary, money may mitigate each of these problems. In any case, one typically comes face to face with these sources of inefficiency only when modeling an economy in a setting that is sufficiently rich to encompass money in a non-trivial way.

One notes that incompleteness of markets (i) is merely evidence of nonconvexities in the transactions technology (iii). With lump-sum costs for setting up markets, a non-convexity, entrepreneurs or governmental authorities will naturally neglect to set up every possible market. Indeed, market completeness may be evidence of inefficiency, in that too many resources may have been allocated to setting up markets. Furthermore, numerous markets imply a low level of activity on each, and further welfare losses can result from overly thin markets. Of course, given non-convexities, the particular structure of incomplete markets that endogenously arises will generally be inefficient. For an exception, see Duffie and Jackson (1989); for an example of an equilibrium allocation that Pareto dominates another equilibrium allocation generated by the addition of a market, see Hart (1975). We have more to add shortly concerning inefficiency and indeterminacy in the context of a smooth model of financial market incompleteness. As for production non-convexities in general equilibrium, there is a large and growing theory on existence and inefficiencies. Readers may consult Guesnerie (1984) for a survey, and Bonnissęau and Cornet (1986a, 1986b), Cornet (1986), as well as Dehez and Drèze (1986) for recent contributions. One contemplates a model in which, due to non-convexities in the technology of setting up and maintaining markets, a central authority might step in to operate markets (maximizing an objective function that eludes this author). Bonnisseau and Cornet, for example, show the existence of equilibria with a large class of objectives for the firm (here, the exchange authority), provided the firm can allocate costs or profits by some scheme such as profit shares, taxes, or subsidies. As far as existence is concerned, one can alternatively exploit the effects of a large number of small agents in convexifying the excess demand correspondence. For two applications of this idea to the existence of monetary equilibrium, see Heller and Starr (1976), who obtain approximate equilibria for a large finite number of agents using the Shapley-Folkman theorem, and Gale and Hellwig (1984), who follow Hildenbrand (1974) in exploiting the convexifying effects of a nonatomic measure space of agents. [See Yamazaki (1989).]

Inefficiencies caused by variation in buying and selling prices (ii) can be ameliorated in two ways. First, brokerage firms can undertake to provide certain transactions services. If the technology is convex, value-maximizing 
firms (in complete markets) will produce and allocate transactions services in a Pareto-optimal manner. In a completely brokered transactions model, the bid-ask spread is then merely replaced by the price of transactions services, and the usual assumptions and arguments imply efficiency. Completely brokered and completely individualistic transactions models are at opposite ends of a spectrum that seems to have been hiding from the eyes of theorists. Second, the notion of efficiency used in the simple model of Section 2 already accounts for the fact that transactions technologies are individualistic. Relative to this constraint, we may still have inefficiencies caused by the value of money itself. In our proof of existence, the relative size of the bid-ask spread can be made arbitrarily small by choosing the matrix $\bar{\Lambda}$ arbitrarily close to the identity matrix, meaning an arbitrarily small value of money relative to goods. As the relative value of money shrinks to zero, buying prices converge to selling prices, and price distortions caused by endowments of money can be made arbitrarily small. Thus, relative to the transactions technology, we may have large or arbitrarily small inefficiencies. This is also a source of real indeterminacy in equilibrium allocations, it seems.

\subsection{Incomplete markets with inside money: Indeterminacy and inoptimality}

Although many of the above comments are speculative, we do have a specific model of existence, inoptimality, and indeterminacy of equilibrium in incomplete markets with money. Although we limit ourselves to the case of inside money so as to apply currently available results, there should be little doubt that the following conclusions extend in a natural way to outside money and the equilibrium notion used in the simple model of Section 2.

We take two periods of trade, with uncertainty in the form of a random state $s \in\{1, \ldots, S\}$ to be revealed in the second period. With $l$ commodities, the consumption space is thus $\mathbb{R}^{L}$, with $L=l(S+1)$. The initial period component of a typical bundle $x \in \mathbb{R}^{L}$ is denoted $x_{1} \in \mathbb{R}^{l}$; the final period component in state $s$ is denoted $x_{2}(s) \in \mathbb{R}^{l}$, for each $s \in\{1, \ldots, S\}$. Similarly, spot commodity prices are represented by a price vector $p \in \mathbb{R}^{L}$ of the form $\left(p_{1}, p_{2}(1), p_{2}(2), \ldots, p_{2}(S)\right)$. Securities, $N$ in number and represented by an $S \times N$ dividend matrix $d$, are available for trade in the initial period. The $(s, n)$-element of $d$ is the number of units of account paid to a holder of one unit of the $n$th security in state $s$ of the final period, just as in the original model of Arrow (1953). The initial prices of the $N$ securities are given by a vector $q \in \mathbb{R}^{N}$. We always take it that the first security is money, meaning that $d_{s 1}=1$ for all $s \in\{1, \ldots, S\}$ and that $q_{1}=1$. Agents are not endowed with securities; they are held in zero net supply. In particular, we are dealing with inside money, which may be borrowed (held negatively, as a credit instrument). 
Leaving transactions costs out of the picture, the $m$ agents are represented by a preference relation $\geq_{i} \subset \mathbb{R}_{+}^{L} \times \mathbb{R}_{+}^{L}$ and an endowment $\omega^{i} \in_{+}^{L}$, for each $i \in$ $\{1, \ldots, m\}$. Each agent chooses a consumption plan $x \in R_{+}^{L}$ and a security portfolio $\theta \in R^{N}$. Given prices $(p, q)$ for commodities and securities, a plan $(x, \theta) \in R_{+}^{L} \times R^{N}$ is budget feasible for agent $i$ if initially budget feasible:

$$
p_{1} \cdot\left(x_{1}-\omega_{1}^{i}\right)+q \cdot \theta \leq 0,
$$

and if budget feasible in each terminal state $s \in\{1, \ldots, S\}$ :

$$
p_{2}(s) \cdot\left[x_{2}(s)-\omega_{2}^{i}(s)\right] \leq d_{s} \theta,
$$

where $d_{s}$ is the $s$ th row of $d$. If $N=1$, or money is the only security, this is a pure consumption-loan model, such as that faced by one generation of an overlapping generations model. If $N<S$, markets are incomplete; there are some consumption plans that cannot be financed by any portfolio of securities. A budget feasible plan $(x, \theta)$ for agent $i$ is optimal for $i$ if there is no budget feasible plan $\left(x^{\prime}, \theta^{\prime}\right)$ for $i$ such that $x^{\prime}>_{i} x$. An equilibrium is a collection

$$
\left[\left(x^{1}, \theta^{1}\right), \ldots,\left(x^{m}, \theta^{m}\right), p, q\right] \in\left(\mathbb{R}_{+}^{L} \times \mathbb{R}^{n}\right)^{m} \times \mathbb{R}^{L} \times \mathbb{R}^{N}
$$

such that, for each agent $i \in\{1, \ldots, m\}$, the plan $\left(x^{i}, \theta^{i}\right)$ is optimal for $i$ given prices $(p, q)$ for consumption and securities, and such that markets clear: $\sum_{i} x^{i}-\omega^{i}=0$ and $\sum_{i} \theta^{i}=0$. Existence of equilibria in this model was first shown by Werner (1985) and Cass (1984). The following result is from Duffie (1987), which gives much weaker conditions than (A.6) and (A.7).

Theorem 2. Under assumption (A.6) and (A.7), there exist equilibria for the incomplete markets model $\left[\left(\geq_{i}, \omega_{i}\right), d\right]$. Moreover, for any $\lambda \in \mathbb{R}_{++}^{S}$ with $\sum_{s} \lambda_{s}=1$, there exists an equilibrium

$$
\left[\left(x^{\lambda 1}, \theta^{\lambda 1}\right), \ldots,\left(x^{\lambda m}, \theta^{\lambda m}\right), p^{\lambda}, q^{\lambda}\right]
$$

with $q^{\lambda}=d^{\top} \lambda$.

The second part of the theorem states that for any state price vector $\lambda$ [an interior element of the $(S-1)$-dimensional unit simplex], there exists an equilibrium in which the market value of any security is merely the value of its state-contingent future dividends, discounted at the given state prices $\lambda$. Normalizing state prices to the unit simplex guarantees that money retains its role as a numeraire. The indeterminacy in security valuation shown in Theorem 2 suggests the potential for indeterminacy in the real allocation, 
which has indeed been shown by Geanakoplos and Mas-Colell (1985), Balasko and Cass (1989), and Werner (1986). To illustrate this indeterminacy, and to contrast with the results of Debreu (1972), who showed that complete markets equilibrium allocations are locally unique, we record the following version of Debreu's smooth preference assumptions.

(A.6') For each agent $i$, the preference relation $\geq_{i}$ is represented by a continuous utility function $u_{i}: \mathbb{R}_{+}^{L} \rightarrow \mathbb{R}$ with the following properties at each $x \in \mathbb{R}_{++}^{L}$ :

(i) $u_{i}$ is three times continuously differentiable (smooth),

(ii) the first partial derivative $D u_{i}(x)$ is in $\mathbb{R}_{++}^{L}$ (strictly monotone),

(iii) $h^{\top} D^{2} u_{i}(x) h<0$ for all non-zero $h \in \mathbb{R}^{L}$ such that $D u_{i}(x) h=0$ (differentiably strictly convex preferences), and

(iv) the closure of $\left\{y \in \mathbb{R}_{+}^{L}: u_{i}(y) \geq u_{i}(x)\right\}$ is contained by $\mathbb{R}_{++}^{L}$.

The boundary condition (iv) states roughly that a bundle with some of every good is better than any bundle with nothing of some good. Assumption (A.6') is satisfied, for example, by Cobb-Douglas utility functions.

Theorem 2 allows for $S-1$ degrees of freedom in security valuation. Is there a similar degree of freedom in the equilibrium allocation $\left(x^{\lambda 1}, \ldots, x^{\lambda m}\right)$ as the state price vector $\lambda$ varies in the $(S-1)$-dimensional simplex? The answer is essentially "Yes, for most economies", as shown by Geanakoplos and MasColell (1985) and Cass (1985). Specifically, we say the dimension of real allocational indeterminancy of $\left(\left(\geq_{i}, \omega_{i}\right), d\right)$ is $n$ if the set of equilibrium allocations for the economy contains a subset diffeomorphic to the interior of the $n$-dimensional unit simplex. We parameterize an economy by its endowment vector $\omega=\left(\omega^{1}, \ldots, \omega^{m}\right) \in \mathbb{R}_{+}^{m L}$, and say that a condition holds generical$l y$ if it holds for all endowments $\omega$ except those in a closed subset of $\mathbb{R}_{+}^{m L}$ of Lebesgue measure zero. We add the following regularity conditions on the dividend matrix $d$.

(A.8) $1 \leq N<m$.

An $S \times N$ matrix with $N \leq S$ is in general position if every $N \times N$ sub-matrix formed by deleting rows is non-singular.

(A.9) $d$ is in general position.

Theorem 3 (Geanakoplos and Mas-Colell). Suppose $N<S$ (incomplete markets). Under conditions (A.6'), (A.8), and (A.9), generically the dimension of real allocational indeterminacy is $S-1$. 
Our interpretation, parameterizing the indeterminacy by the state price vector $\lambda$, is given in the method of proof of Werner (1986). While some have claimed that a useful model of monetary equilibria should exhibit determinacy of the allocation, one cannot simply wish away the allocational degrees of freedom apparent in this result. Presumably aspects of the economy that are yet to be modeled, perhaps calling for a non-Walrasian model, also play a role in determining the equilibrium allocation. It has been apparent for some time in the overlapping generations genre of models that money plays a role in the indeterminacy of allocations. [Santos and Bona (1986) may represent the state of this art.] An examination of the source of Theorem 3 shows that the indeterminacy does not depend on one of the securities being money. Furthermore, if there are no securities $(N=0)$ or no uncertainty $(S=1)$, the indeterminacy disappears.

For incomplete markets, Geanakoplos and Polemarchakis (1986) define a notion of constrained sub-optimality of the following sort. Given prices $(p, q)$, a budget feasible plan $(x, \theta)$ for agent $i$ is spot optimal for $i$ if there is no consumption plan $x^{\prime}$ such that $\left(x^{\prime}, \theta\right)$ is budget feasible and $x^{\prime}>_{i} x$. A fixed portfolio equilibirum is a collection

$$
\left[\left(x^{1}, \theta^{1}\right), \ldots,\left(x^{m}, \theta^{m}\right), p, q\right] \in\left(\mathbb{R}_{+}^{L} \times \mathbb{R}^{N}\right)^{m} \times \mathbb{R}^{L} \times \mathbb{R}^{N}
$$

such that, given prices $(p, q)$, for each agent $i$ the plan $\left(x^{i}, \theta^{i}\right)$ is spot optimal, and markets clear. In particular, an equilibrium is a fixed portfolio equilibrium. An equilibrium allocation $a=\left(\left(x^{1}, \theta^{1}\right), \ldots,\left(x^{m}, \theta^{m}\right)\right)$ for the incomplete markets economy $\left(\left(\geq_{i}, \omega_{i}\right), d\right)$ is constrained sub-optimal if, for any $\epsilon>0$, there exists a fixed portfolio equilibrium allocation $\bar{a}=\left(\left(\bar{x}^{1}, \bar{\theta}^{1}\right), \ldots,\left(\bar{x}^{m}, \bar{\theta}^{m}\right)\right)$ with $\|a-\bar{a}\| \leq \epsilon$ such that $\left(\bar{x}^{1}, \ldots, \bar{x}^{m}\right)$ Pareto dominates $\left(x^{1}, \ldots, x^{m}\right)$. Under the same preference assumptions (A.6), and with a slightly different model, Geanakoplos and Polemarchakis give additional regularity conditions under which incomplete markets equilibria are generically constrained sub-optimal. (Here, the result is generic with respect to both endowments and preferences.) In other words, at equilibrium, a central planner could make a slight change in portfolios so as to improve the resulting market-clearing consumption allocation.

\section{Concluding remark}

To repeat, the aims of this chapter are extremely narrow relative to those of the modern literature on monetary equilibrium theory. Grandmont (1983), on the other hand, is an excellent synthesis of classical and neoclassical theories of monetary equilibria. 


\section{References}

Arrow, K. (1951) 'An extension of the basic theorems of classical welfare economics', in: J. Neyman, ed., Proceedings of the Second Berkeley Symposium on Mathematical Statistics and Probability. Berkeley: University of California Press.

Arrow, K. (1953) 'Le rôle des valeurs boursières pour la répartition la meillure des risques', Econometrie, pp. 41-47; discussion, pp. 47-48, Colloq. Internat. Centre National de la Recherche Scientifique, no. 40 (Paris, 1952) C.N.R.S. Paris, 1953; translated in Review of Economic Studies, 31 (1964): 91-96.

Arrow, K. and G. Debreu (1954) 'Existence of an equilibrium for a competitive economy' Econometrica, 22: 265-290.

Balasko, Y and D. Cass (1989) 'The structure of financial equilibrium with exogenous yields: The case of incomplete markets', Econometrica, 57: 135-162.

Balasko, Y. and K. Shell (1980) 'The overlapping-generations model, Part I', Journal of Economic Theory, 23: $281-306$.

Balasko, Y. and K. Shell (1981a) 'The overlapping-generations model, Part II', Journal of Economic Theory, 24: 112-142.

Balasko, Y. and K. Shell (1981b) 'The overlapping-generations model, Part III', Journal of Economic Theory, 24: 143-152.

Baumol, W. (1952) 'The transactions demand for cash: An inventory theoretic approach', Quarterly Journal of Economics, 66: 545-556.

Bewley, T. (1980) 'The optimum quantity of money', in: J. Kareken and N. Wallace, eds., Models of monetary economics. Minneapolis: Federal Reserve Bank of Minneapolis.

Bewley, T. (1984) 'Fiscal and monetary policy in a general equilibrium model', Working Paper 690, Cowles Foundation for Research in Economics at Yale University.

Black, F. (1974) 'Uniqueness of price level in monetary growth models with rational expectations', Journal of Economic Theory, 7: 53-65.

Bonnisseau, J.-M. and B. Cornet (1986a) 'Existence of equilibria when firms follow bounded losses pricing rules', Research Paper 8607, CORE, Louvain-La-Neuve, Belgium.

Bonnisseau, J.-M. and B. Cornet (1986b) 'Existence of marginal cost pricing equilibria in an economy with several non convex firms', Unpublished, CERMSEM, Université Paris I.

Brock W. (1974) 'Money and growth: The case of long-run perfect foresight', International Economic Review, 15: 750-777.

Bryant, J. and N. Wallace (1983) 'A suggestion for further simplifying the theory of money', Research Paper 62, Federal Reserve Bank of Minneapolis, Research Department.

Cass, D. (1984) 'Competitive equilibrium with incomplete financial markets', CARESS Working Paper 84-09, University of Pennsylvania.

Cass, D. (1985) "On the "Number" of equilibrium allocations with incomplete financial markets', CARESS Working Paper 85-16, University of Pennsylvania.

Cass, D., M. Okuno and I. Zilcha (1979) 'The role of money in supporting the Pareto optimality of competitive equilibrium in consumption loan type models', Journal of Economic Theory, 20: 41-80.

Clower, R. (1967) 'A reconsideration of the microfoundations of monetary theory', Western Economic Journal, 6: 1-9.

Cornet, B. (1986) 'The second welfare theorem in nonconvex economies', Unpublished, Université Paris I, Panthéon-Sorbonne, and CORE, Université Catholique de Louvain, Belgium.

G. Debreu (1954) 'Valuation equilibrium and Pareto optimum', Proceedings of the National Academy of Sciences, 40: 588-592.

G. Debreu (1970) 'Economies with a finite set of equilibria', Econometrica, 38: 387-392.

G. Debreu (1972) 'Smooth preferences', Econometrica, 40: 603-615.

G. Debreu (1976) 'Smooth preferences: A corrigendum', Econometrica, 44: 831-832.

Dehez, P. and J. Drèze (1986) 'Competitive equilibria with increasing returns', Research Paper 8623, CORE, Louvain-la-Neuve, Belgium.

Duffie, D. (1987) 'Stochastic equilibria with incomplete financial markets', Journal of Economic Theory, 41: 405-416; Corrigendum, 49: 384. 
Duffie, D. and M. Jackson (1989) 'Optimal innovation of futures contracts', Review of Financial Studies, 2: 275-296.

Foley, D. (1970) 'Economic equilibrium with costly marketing', Journal of Economic Theory, 2: 276-291.

Friedman, M. (1969) The optimum quantity of money. Chicago: Aldine.

Gale, D. (1982) Money: In equilibrium. Cambridge University Press.

Gale, D. and M. Hellwig (1984) 'A general-equilibrium model of the transactions demand for money', CARESS Working Paper 85-07, University of Pennsylvania.

Geanakoplos, J. and A. Mas-Colell (1985) 'Real indeterminacy with financial assets', Unpublished, Cowles Foundation, Yale University.

Geanakoplos, J. and H. Polemarchakis (1986) 'Existence, regularity, and constrained suboptimality of competitive portfolio allocations when the asset market is incomplete', in: W.P. Heller and D.A. Starrett, eds., Uncertainty information and communication. Essays in honor of Kenneth J. Arrow, Vol. III. Cambridge University Press.

Grandmont, J.-M. (1983) Money and value: A reconsideration of classical and neoclassical theories. Cambridge University Press.

Green, J. and E. Sheshinski (1975) 'Competitive inefficiencies in the presence of constrained transactions', Journal of economic Theory, 10: 343-357.

Guesnerie, R. (1984) 'First best allocation of resources with non convexities in production', Unpublished, Ecole des Hautes Etudes en Sciences Sociales, Paris.

Hahn, F. (1965) 'On some problems of proving the existence of an equilibrium in a monetary economy', In: F. Hahn and F. Brechling, eds., The theory of interest rates. London: Macmillan.

Hahn, F. (1971) 'Equilibrium with transaction costs', Econometrica, 39: 417-439.

Hahn, F. (1973a) 'On the foundations of monetary theory', in: M. Parkin and A. Nobay, eds., Essays in Modern Economics. Longman Group.

Hahn, F. (1973b) 'On transaction costs, inessential sequence economies, and money', Review of Economic Studies, 40: 449-461.

Hahn, F. (1980) 'Discussion', in: J. Kareken and N. Wallace, eds., Models of monetary Economies. Minneapolis: Federal Reserve Bank of Minneapolis.

Hahn, F. (1983) Money and inflation. Cambridge, Mass.: MIT Press.

Hart, O. (1975) 'On the optimality of equilibrium when the market structure is incomplete', Journal of Economic Theory, 9: 53-83.

Hayashi, T. (1974) 'The non-Pareto efficiency of initial allocation of commodities and monetary equilibrium: An inside money economy', Journal of Economic Theory, 7: 173-187.

Heller, W. (1972) 'Transactions with set-up costs', Journal of Economic Theory, 4: 465-478.

Heller, W. (1974) 'The holding of money balances in general equilibrium', Journal of economic Theory, 7: 93-108.

Heller, W. and R. Starr (1976) 'Equilibrium with non-convex transactions costs: Monetary and non-monetary economies', Review of Economic Studies, 43: 195-215.

Hicks, J. (1935) 'A suggestion for simplifying the theory of money', Economica, 2: 1-19.

Hildenbrand, W. (1974) Core and equilibria of a large economy. Princeton University Press.

Honkapohja, S. (1978) 'On the efficiency of a competitive monetary equilibrium with transaction costs', Review of Economic Studies, 45: 405-415.

Kurz, M. (1974a) 'Arrow-Debreu equilibrium of an exchange economy with transaction cost', International Economic Review, 15: 699-717.

Kurz, M. (1974b) 'equilibrium in a finite sequence of markets with transaction cost', Econometrica, 42: $1-20$.

Kurz, M. (1974c) 'Equilibrium with transaction cost and money in a single market exchange economy', Journal of Economic Theory, 7: 418-452.

Levine, D. (1985a) 'Efficiency and the value of money', Unpublished, University of California, Los Angeles.

Levine, D. (1985b) 'Liquidity with random market closure', Research Paper 85, University of Cambridge, Economic theory Discussion Paper.

Miller, M. and D. Orr (1956) 'A model of the demand for money by firms', Quarterly Journal of Economics, 80: 413-435. 
Okuno, M. (1973) 'Essays on monetary equilibrium in a sequence of markets', Technical Report 120 , Institute for Mathematical Studies in the Social Sciences.

Ostroy, J. and R. Starr (1974) 'Money and the decentralization of exchange', Econometrica, 42: $1093-1113$.

Radner, R. (1972) 'Existence of equilibrium of plans prices and price expectations in a sequence of markets', Econometrica, 40: 1135-1191.

Santos, M. and J. Bona (1986) 'On the structure of the equilibrium price set of overlappinggenerations economies', Unpublished, Department of Mathematics, University of Chicago.

Sontheimer, K. (1972) 'On the determination of money prices', Journal of Money, Credit and Banking, 4: 489-508.

Starr, R. (1972) 'The structure of exchange in barter and monetary economies', Quarterly Journal of Economics, 86: 290-302.

Starr, R. (1974) 'The price of money in a pure exchange monetary economy with taxation', Econometrica, 42: 45-54.

Starrett, D. (1973) 'Inefficiency and the demand for "money" in a sequence economy', Review of Economic Studies, 40: 437-448.

Tobin, J. (1956) 'The interest elasticity of transactions demand for cash', Review of Economics and Statistics, 38: 241-247.

Werner, J. (1985) 'Equilibrium in economies with incomplete financial markets', Journal of Economic Theory, 36: 110-119.

Werner, J. (1986) 'Asset prices and real indeterminacy in equilibrium with financial markets', Unpublished, University of Bonn.

Woodford, M. (1986) 'Asset bubbles and fiat money', Unpublished, University of Chicago and New York University.

Yamazaki, A. (1989) 'Monetary equilibria in a continuum economy with general transaction economies', RUEE Working Paper 89-39, Department of Economics, Hitotsubashi University, Tokyo, Japan. 